\title{
Study on the Early Warning of PPP Project Risk based on Rough Set and BP Neural Network
}

\author{
Daoping Wang ${ }^{1,}$ a , Zhe Wang ${ }^{1, b}$ and Xiaojuan Sheng ${ }^{2, c}$ \\ ${ }^{1}$ Donlinks School of Economics and Management, University of Science and Technology Beijing, \\ Beijing, 100083, P.R. China \\ ${ }^{2}$ Management School, Beijing Union University, Beijing, 100101, P.R. China

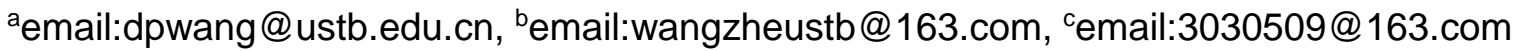

\begin{abstract}
Keywords: PPP Project; Early Warning; Rough Set; BP Neural Network
Abstract. The risk of PPP project is one of the issues the most importantly focused by all participants in the project management; the establishment of a scientific risk early warning system is an effective way to control the risk of PPP projects. Based on the design of the PPP project risk early warning index system, the evaluation indexes were subtracted with rough set; a nonlinear simulation early warning model of PPP project risk was constructed with BP neural network; the network model was simulated through the sample data to obtain a good simulation effect.
\end{abstract}

\section{Introduction}

PPP (Public-private-partnership, the government and social capital cooperation) project is a cooperation model, in which the government preferentially chooses the social capital through competition, provides public services through social capital, and pays the corresponding price according to the performance evaluation. PPP project features large investment amounts, multiple capital source channels, long project cycle, and diversity of participants and so on; and therefore, within the whole life cycle of PPP project, there are many complicated risks and great negative impact will be exerted on society and economy once problems occur. As the status and role of PPP project in the infrastructure construction are becoming more and more important, it is especially important to timely prevent and respond the risks of PPP project in time.

In the researches on PPP project risk responses, Cheng ${ }^{[1]}$ established a risk evaluation model based on Delphi method, fuzzy mathematics method and AHP method and also used it to choose the BOT traffic project in Taiwan. Thomasctal ${ }^{[2]}$ put forward the PPP project risk assessment method framework of fault tree method and Delphi method. Chen ${ }^{[3]}$ evaluated the risks of PPP project using the fuzzy comprehensive evaluation method. W. Zhang ${ }^{[4]}$ analyzed the main risk factors using the network analytic hierarchy process. $\mathrm{Jia}^{[5]}$ studied the project risks using entropy weight method and Grey relation theory.

Because the risks of PPP project feature multiple risk factors, few samples and non-linearity, after the redundant risk indexes were reduced with the rough set, this paper constructed a well-evaluated, early-warning system using the BP neural network characteristics such as good at dealing with nonlinear problems, self-adaptive learning and strong fault tolerance ${ }^{[6]}$, so as to help government and enterprises carry out comprehensive and effective risk early warning and management for PPP projects.

\section{PPP project risk warning index system}

The quality of PPP project risk early warning index system directly affects the risk early warning effect; it is required to comprehensively, accurately and effectively respond all sorts of risk factors in the implementation process of PPP projects. Through extensively consulting the related domestic and foreign literature materials, the involved PPP project risk factors were analyzed and reorganized; all sorts of risk bases emerging in the implementation process of domestic and foreign PPP projects were integrated; the project risks were divided into 6 primary indexes and 38 secondary indexes according 
to the principles of comprehensiveness, systematicness, scientificity and comparability and the expressive forms of PPP project's decision, investment and financing, construction and operation phases; on these grounds, a PPP project risk early warning index system was constructed (see table 1).

Table 1: PPP project risk early warning index system

\begin{tabular}{|c|c|c|c|c|c|}
\hline Class I Index & Class II Index & $\begin{array}{l}\text { Attribution } \\
\text { of Indix }\end{array}$ & Class I Index & Class II Index & $\begin{array}{l}\text { Attribution } \\
\text { of Indix }\end{array}$ \\
\hline \multirow{6}{*}{$\begin{array}{l}\text { Policy and } \\
\text { legal risk A1 }\end{array}$} & $\begin{array}{l}\text { The degree of government } \\
\text { credit A11 }\end{array}$ & Qualitative & \multirow{4}{*}{$\begin{array}{l}\text { Construction } \\
\text { risk A3 }\end{array}$} & $\begin{array}{l}\text { Construction cost control } \\
\text { A36 }\end{array}$ & Qualitative \\
\hline & $\begin{array}{l}\text { GDP growth of local } \\
\text { government A12 }\end{array}$ & Quantitative & & Site safety A37 & Qualitative \\
\hline & $\begin{array}{lrr}\text { Timeliness } & \text { of } & \text { project } \\
\text { approval } & \text { A13 } & \end{array}$ & Qualitative & & $\begin{array}{l}\text { Timeliness of material } \\
\text { supply A38 }\end{array}$ & Qualitative \\
\hline & Change of tax system A14 & Qualitative & & Environmental damage A39 & Qualitative \\
\hline & $\begin{array}{l}\text { Degree of perfection of legal } \\
\text { supervision A15 }\end{array}$ & Qualitative & \multirow{7}{*}{$\begin{array}{l}\text { Operational } \\
\text { risk A4 }\end{array}$} & Operating period A41 & Quantitative \\
\hline & $\begin{array}{l}\text { Completeness of contract } \\
\text { documents A16 }\end{array}$ & Qualitative & & Operation cost control A42 & Qualitative \\
\hline \multirow{8}{*}{$\begin{array}{l}\text { Investment } \\
\text { and } \\
\text { financing } \\
\text { risk A2 }\end{array}$} & Investment amount A21 & Quantitative & & $\begin{array}{l}\text { Timeliness of government } \\
\text { subsidies A43 }\end{array}$ & Qualitative \\
\hline & Capital ratio A22 & Quantitative & & $\begin{array}{l}\text { User pays less than expected } \\
\text { A44 }\end{array}$ & Qualitative \\
\hline & $\begin{array}{l}\begin{array}{l}\text { Share ratio } \\
\text { government and } \\
\text { investors A23 }\end{array} \\
\text { intween } \\
\end{array}$ & Quantitative & & Operation quality A45 & Qualitative \\
\hline & $\begin{array}{l}\text { The proportion of pre } \\
\text { project cost to total } \\
\text { investment A24 }\end{array}$ & Quantitative & & Facilities maintenance A46 & Qualitative \\
\hline & Financing environment A25 & Qualitative & & $\begin{array}{l}\text { Performance evaluation of } \\
\text { operation and maintenance } \\
\text { A47 }\end{array}$ & Qualitative \\
\hline & Financing cost A26 & Quantitative & \multirow{5}{*}{$\begin{array}{l}\text { Cooperation } \\
\text { risk A5 }\end{array}$} & $\begin{array}{l}\text { Rationality of responsibility } \\
\text { distribution A51 }\end{array}$ & Qualitative \\
\hline & $\begin{array}{l}\text { Timeliness of Financing in } \\
\text { place A27 }\end{array}$ & Qualitative & & Partner credit level A52 & Qualitative \\
\hline & Change of Interest rate A28 & Qualitative & & $\begin{array}{l}\text { Partner project } \\
\text { implementation experience } \\
\text { A53 }\end{array}$ & Qualitative \\
\hline \multirow{5}{*}{$\begin{array}{l}\text { Construction } \\
\text { risk A3 }\end{array}$} & Construction period A31 & Quantitative & & Contract disputes A54 & Qualitative \\
\hline & $\begin{array}{l}\text { Demolition cost overruns } \\
\text { A32 }\end{array}$ & Qualitative & & $\begin{array}{l}\text { Organizational coordination } \\
\text { A55 }\end{array}$ & Qualitative \\
\hline & Design change A33 & Qualitative & \multirow{3}{*}{$\begin{array}{l}\text { Natural risk } \\
\text { A6 }\end{array}$} & Climatic conditions A61 & Qualitative \\
\hline & $\begin{array}{l}\text { Delay of construction period } \\
\text { A34 }\end{array}$ & Qualitative & & Geological conditions A62 & Qualitative \\
\hline & $\begin{array}{l}\text { Engineering quality control } \\
\text { A35 }\end{array}$ & Qualitative & & Force majeure A63 & Qualitative \\
\hline
\end{tabular}

\section{The construction of PPP project risk early warning model based on rough set and BP neural network}

Artificial neural network is a new kind of information processing or computing system that developed by imitating the function or structure of the biological nervous system according to the basic functional characteristics of human brain. These large amounts of information processing units constituted a dynamic information processing system through extensive connection, which could reflect the complex, fuzzy, dynamic, random, and nonlinear relationship among multiple factors ${ }^{[7]}$. In 1985, the parallel distributed processing group led by Rumelhart et al proposed an error reverse transfer learning algorithm (i.e. BP algorithm).

As one of the important tools researching complex problems, the BP neural network technology's superiority is very prominent in the aspects such as object classification, pattern recognition, and rating prediction; it possesses high self-study and self-adaption functions, many inside callable parameters, and powerful parallel processing mechanism. Meanwhile, its system is of very strong flexibility and can handle any type of data; through the constant self-study of the system, laws can be 
found from a large amount of unknown complex data to determine the model parameters. Neural network model as a natural nonlinear modeling process does not need to know exactly what relation between different indexes; it is a very convenient method.

BP neural network risk early warning method has been widely applied to the analysis and monitoring of the risks in the credit, market, and operation of commercial banks and securities companies, and it has grown into an important tool for the risk management of financial institutions. BP neural network possesses the ability to "migrate" the risk prediction; that is to say, it can predict the similar data of unknown results after the given sample data was trained. Rough set (RS) ${ }^{[8]}$ is a mathematical theory raised by Polish mathematician Pawlak in 1982 to analyze data; its main idea is to equivalently, effectively simplifying attribute set under the condition that attributes were guaranteed to meet certain classification accuracy and to simply the computation by removing redundant attributes. The reduction of the attributes of rough set did not need any prior information distributed by attributes, and its application results were more objective ${ }^{[9]}$. Thus, reducing the network scale and the burden of network learning and training, enhancing the prediction accuracy of the early warning model, and improving the early warning performance of PPP project risks could be achieved by applying rough set to reduce risk early warning indexes and eliminate table noise and redundant objects and then using BP neural network to learn and train samples (Fig.1). In view of this case, this paper constructed a PPP project risk early warning model based on the combination of rough set and BP neural network in order to realize the risk monitoring and warning of PPP projects.

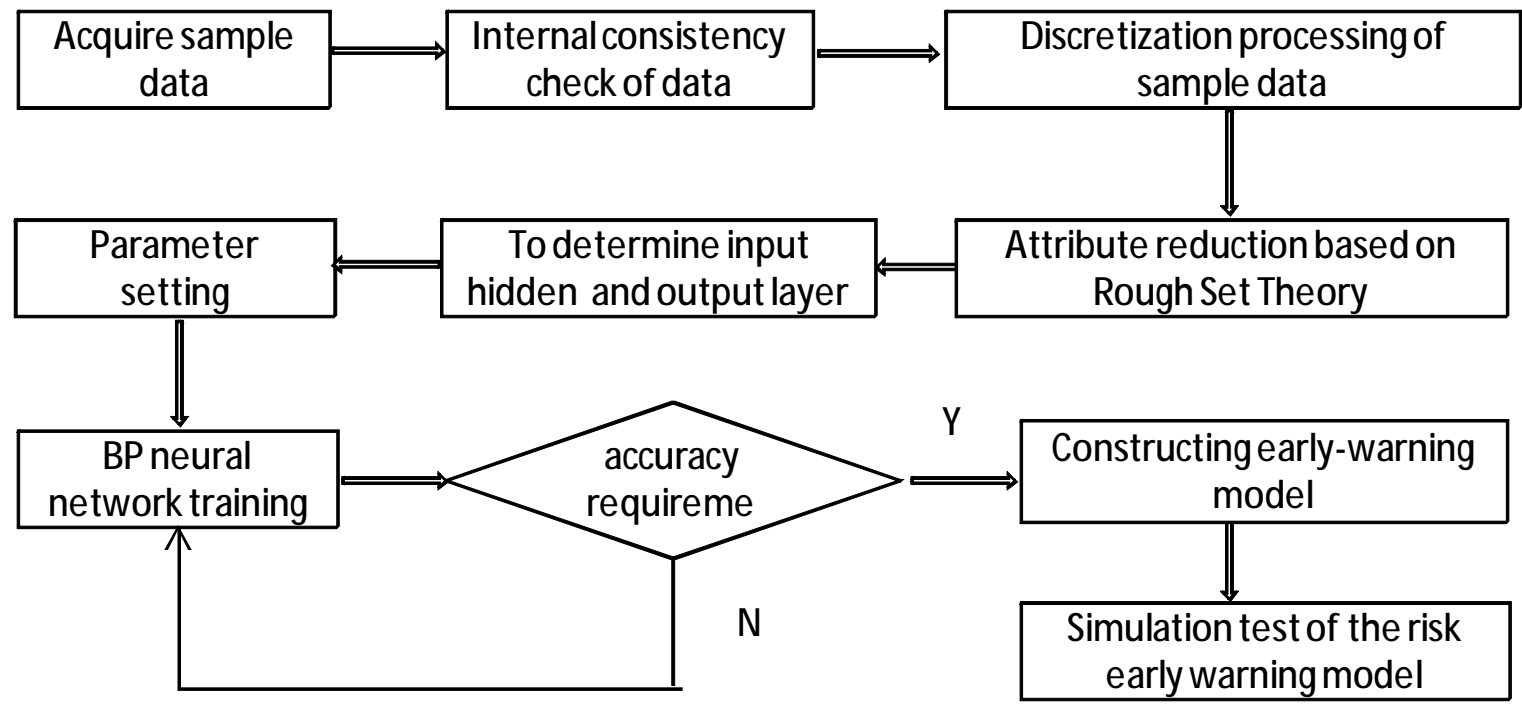

Fig. 1 the PPP project risk early warning system flow design

This paper constructed a PPP project risk early warning model based on rough set and BP neural network (Fig.2). This model included six parts: early warning indexes, rough set reduction preface system, input layer, hidden layer, output layer, and risk warning module. The number of the nodes of the input layer was the number of the early warning indexes characteristic variables reduced by rough set; the number of the output nodes was one and only, the level of risks could be determined according to the output value, and the relevant warning module would be started up by the model according to the level of risks; the selection of the nodes of the hidden layer was determined according to the following formula:

$$
N=\sqrt{a+b}+c
$$

Where,

a-the number of the input nodes;

$\mathrm{b}$ - the number of the output nodes;

c- the constant from 1 to 10

The selection of the weight of the nodes was the arbitrary number of the interval; the weight was constantly corrected and adjusted according to the training result of each function and sample until the error of the model was controlled within the set scope. 


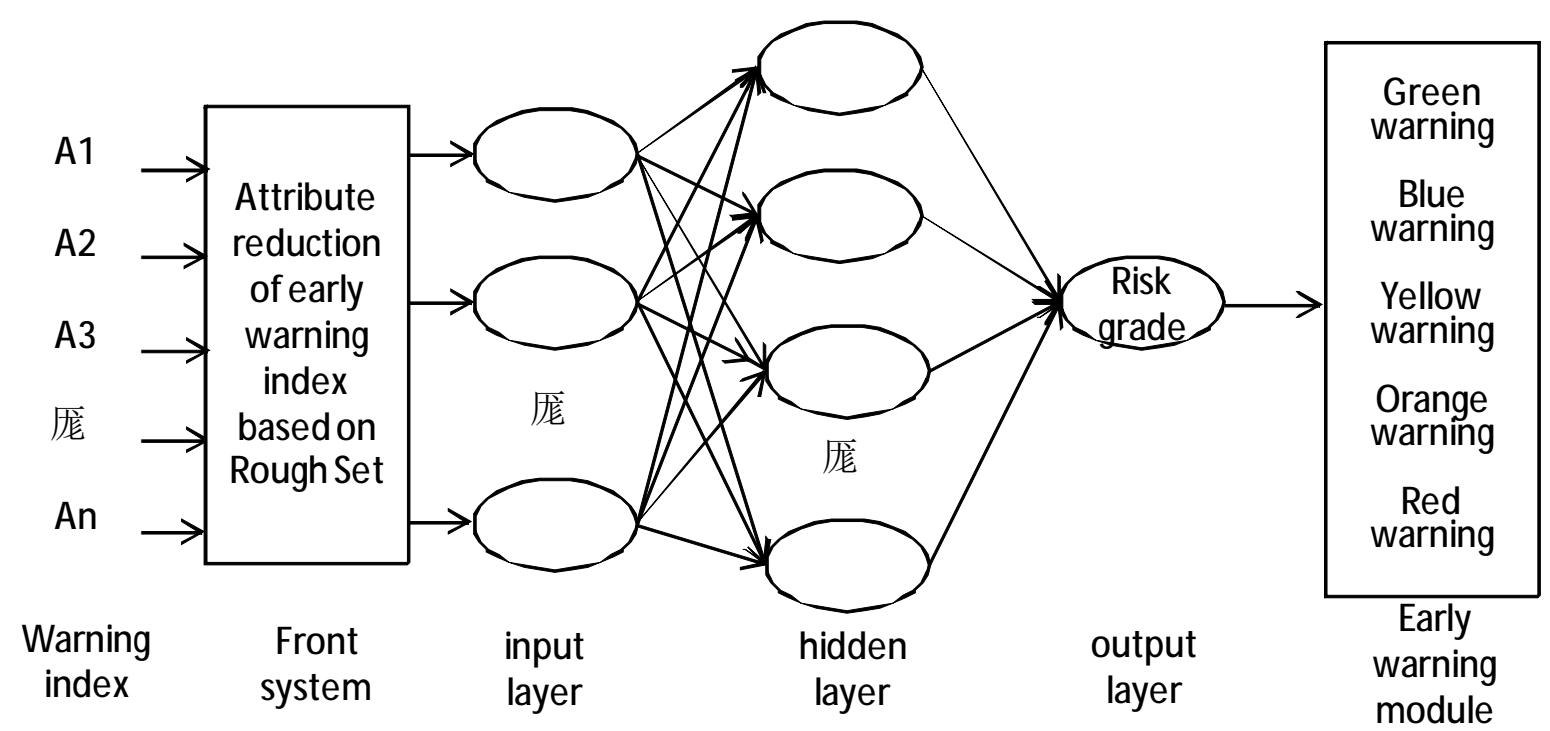

Fig.2 the PPP project risk early warning model structure based on rough set and BP neural network

\section{The application of PPP project risk early warning model}

\section{Training sample collection and basic analysis}

In this paper, the PPP projects of 22 kinds of domestic infrastructure such as highway, municipal administration, and urban rail transit in the operation stage were chosen; the questionnaire design of qualitative indexes was conducted by collecting project data and information; 30 qualitative indexes among 38 risk early warning indexes of 22 projects were rated by 12 persons including PPP field experts, scholars and project company managers; the qualitative indexes in the questionnaire were measured using the Likert Scale, and then options of 5 levels of the qualitative indexes from low to high were set up in the risk early warning index system according to the discernment of the tested objects: 1 - the lowest degree, 2 -represented lower degree, 3-general degree, 4-higher degree; 5 - the highest degree. The arithmetic mean of 12 tested objects' rates, rounded to integer, was used as the value of each quantitative index. 8 quantitative indexes in the index system were determined according to the survey data of the project.

Then, the reliability and validity of the data obtained from the survey was analyzed using SPSS software. The reliability analysis was to calculate the reliability coefficient of each secondary index and the overall reliability of the questionnaire so as to test the internal consistency and reliability of the questionnaire data. The reliability coefficient of each index and the overall reliability coefficient of the questionnaire were estimated mainly using the Cronbach's alpha internal consistency coefficient.

Table 2 the reliability index of the questionnaire

\begin{tabular}{|c|c|c|c|c|c|c|c|}
\hline Reliability Index & A1 & A2 & A3 & A4 & A5 & A6 & Questionnaire \\
\hline Cronbach's $\alpha$ & 0.812 & 0.775 & 0.708 & 0.827 & 0.766 & 0.719 & 0.816 \\
\hline
\end{tabular}

From table2, it was seen that the Cronbach's acoefficient of the six secondary indexes of the questionnaire was $>0.7$, and the overall Cronbach's alpha coefficient of the questionnaire was $>0.8$, indicating that the reliability of the questionnaire met the requirements.

\section{The application of rough set to index reduction}

Based on acquiring the index data for the reliability and validity analysis, the sample data of the quantitative indexes was discretized according to the needs of rough set calculation. Then, according to the basic steps of the rough set to filter early warning indexes, 38 indexes in the PPP project risk early warning index system were firstly used as the conditional attributes; B was used as the decision attribute set. In this study, B represented the risk level of PPP project; by discretizing the continuous 
data, an index attribute decision table was constructed with conditional attributes and decision attributes, as shown in table 3 .

Table 3 the index attribute decision table

\begin{tabular}{|c|c|c|c|c|c|c|c|c|c|c|c|c|c|}
\hline \multirow{2}{*}{ Sample } & \multicolumn{10}{|c|}{ Decision Attribute } \\
\cline { 2 - 10 } & A1 & A2 & A3 & A4 & A5 & A6 & $\ldots$ & A34 & A35 & A36 & A37 & A38 & B \\
\hline \hline 1 & 4 & 3 & 4 & 1 & 3 & 4 & $\ldots$ & 2 & 4 & 2 & 3 & 2 & 2 \\
2 & 3 & 1 & 3 & 2 & 2 & 3 & $\ldots$ & 3 & 2 & 3 & 4 & 1 & 4 \\
3 & 5 & 3 & 5 & 1 & 4 & 4 & $\ldots$ & 1 & 4 & 4 & 4 & 1 & 1 \\
4 & 4 & 5 & 3 & 2 & 3 & 3 & $\ldots$ & 2 & 3 & 4 & 2 & 2 & 3 \\
5 & 3 & 2 & 2 & 1 & 2 & 2 & $\ldots$ & 2 & 3 & 3 & 4 & 2 & 5 \\
$\ldots$ & $\ldots$ & $\ldots$ & $\ldots$ & $\ldots$ & $\ldots$ & $\ldots$ & $\ldots$ & $\ldots$ & $\ldots$ & $\ldots$ & $\ldots$ & $\ldots$ & $\ldots$ \\
22 & 3 & 2 & 3 & 2 & 3 & 2 & $\ldots$ & 4 & 2 & 4 & 2 & 1 & 4 \\
\hline
\end{tabular}

The indexes were reduced using the genetic algorithm in the Rosetta data processing software, and the values of all parameters were as follows: the hybridization probability was 0.3 ; the exchange mutation probability was 0.05 ; the inverse mutation probability was 0.05 ; the population size was 70 ; 20 indexes were totally reduced and 18 indexes including A2 and A3 were retained.

\section{BP neural network training and simulation}

To facilitate the design and training of the neural network, MATLAB provides a neural network tool kit which can be used to call the relevant procedures. In this paper, the function newff() was used for creating the BP neural network. In the Matlab7.0 environment, the first 20 samples in the sample data reduced by the rough set were used as the training samples, and the second 2 samples were used as test samples for data analysis. In the process of training the BP neural network model, by taking the training sample data as the input sample set and the risk-level B as the output sample set, a three-layer neural network training model consisting of input layer, hidden layer and output layer was constructed. The dimension of input layer was 18; the dimension of output layer was 1; the dimension of hidden layer was 15 ; the value of the learning efficiency was 0.001 ; the error precision was 0.0001 and reached the termination error requirement after it underwent iterative training for seven times; as shown in Fig.3, the desired BP neural network model was obtained.

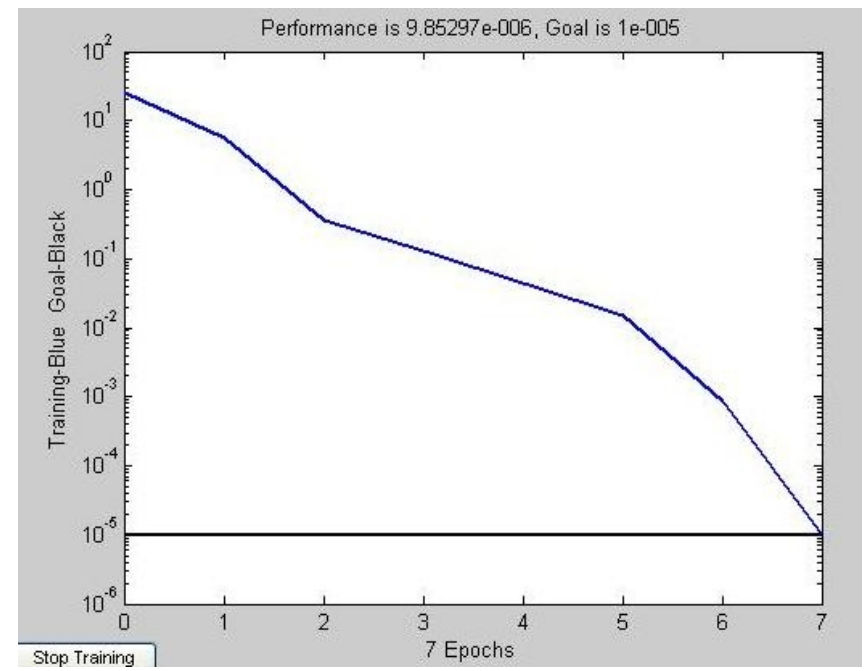

Fig.3 the neural network training error change curve

2 test samples were simulated using trained BP neural network model; after the test results were obtained, the risk-level simulation results of the 2 samples were compared with the actual survey data; from the simulation result in table 4, it was seen that the consistency between the simulation output and the actual survey data was very good. Sample 21 was taken for example: the risk-level survey result of this project was 2: it was a blue warning project; its simulation result obtained with rough set and BP neural network model was 2.0809 , and the simulated effect was up to $97.98 \%$. Thus, it was seen that this model was effective to the PPP project risk early warning. This model could be used for 
carrying out the PPP project risk-level prediction and risk early warning, making the warning result more objective and improving the accuracy of the risk early warning of PPP projects.

Table 4 the comparison of the simulation test result and actual survey result

\begin{tabular}{|c|c|c|c|}
\hline & $\begin{array}{c}\text { Risk level survey } \\
\text { results }\end{array}$ & $\begin{array}{c}\text { Model simulation } \\
\text { results }\end{array}$ & Simulation effect \\
\hline Sample 21 & 2 & 2.0809 & $97.98 \%$ \\
\hline Sample 22 & 4 & 4.0240 & $99.40 \%$ \\
\hline
\end{tabular}

Data explanation: simulated effect=1-|simulation value-survey value//(max(survey value)-min(survey value); epochs was the number of network training; goal was the network training target error

\section{Conclusion}

In this paper, on the basis of constructing a PPP project risk early warning index system, the early warning indexes were reduced using rough set in order to eliminate the redundant indexes and noise interference. Then, a BP neural network early warning model was constructed using the BP neural network; through training the sample data, the consistency between the simulated result of the model and the expected output data was very good, and the simulation effect was higher than $97 \%$.

Through the strict monitoring of the PPP project risk early warning model, different measures could be taken according to the risk levels of PPP projects; for example, contact would be taken for green warning, tracking would be used for blue warning; risk screening and treatment measures would be adopted for yellow warning; working group would be organized for orange warning to carry out the site investigation and research and make a special risk solution; all means and measures would be taken by all participants for red warning to ensure project implementation and the rights and interests of investors. By using this model to carry on the risk-level early warning, the PPP project risks could be dynamically tracked; quantifying the risks and automatically warning the risks are advantageous for the regulators and the project participants to timely take effective measures to dissolve the project risks, making the PPP projects operated stably and ultimately promoting the healthy development of the PPP model in China.

\section{References}

[1] J. H. Cheng. "A view of public and private sectors for Taiwan's BOT transportation project financing using fuzzy multi-criteria methods." The, IEEE International Conference on Fuzzy Systems IEEE, 2002:356-359.

[2] A. V. Thomas, Satyanarayana N. Kalidindi, and L. S. Ganesh. "Modelling and assessment of critical risks in BOT road projects." Construction Management \& Economics 24.4(2006):407-424.

[3] J.W.Chen., et al. "Research on PPP project risk based on fuzzy comprehensive evaluation method ." Journal of Hebei University of Technology. 35. 5(2006): 46-50.

[4] W. Zhang and W. D. Zhang. "Research on PPP project risk evaluation based on network analytic hierarchy process." Project management technology. 10.10(2012):84-88.

[5] L.L.Jia and X. He. "Study on the evaluation of financing mode risk of urban rail transit in the PPP project ." Journal of Shijiazhuang Railway University (SOCIAL SCIENCE EDITION). 7. 4(2013):29-33.

[6] Goh, A. T. C. "Back-propagation neural networks for modeling complex systems." Artificial Intelligence in Engineering 9.3(1995):143-151.

[7] P. Zheng and J. Li. "Back Propagation Neural Network Approach on Supply Chain Dynamic Performance Measurement." Operations Research \& Management Science (2010). 
[8] Pawlak, Zdzislaw. "Rough Sets International Journal of Information and Computer Sciences." (1982).

[9] Greco, Salvatore, B. Matarazzo, and R. Slowinski. "Rough sets theory for multicriteria decision analysis." European Journal of Operational Research 129.1(2001):1-47. 